INNOVATIONS IN PRIMARY CARE

\title{
Running Medicine: Mind, Body, and Spirit Wellness Through Walking and Running
}

\author{
Anthony Fleg, MD, MPH $\quad$ Stacie Hurley ${ }^{1}$ \\ Danielle Kie ${ }^{1}$ \\ Lynette Padilla \\ Rod Lansing ${ }^{1}$ \\ 'Native Health Initiative, Albuquerque, New Mexico \\ ${ }^{2}$ University of New Mexico Family and Community Medicine, \\ Albuquerque, New Mexico
}

Ann Fam Med 2019;17:466. https://doi.org/10.1370/afm.2417.

\section{THE INNOVATION}

Getting our patients and communities moving is challenging, with too few outlets for families to exercise together in lowcost, inclusive spaces. Running Medicine (RM) (https://runningmedicine.org) came from a vision of the Native Health Initiative (NHI) to provide such a program. Running Medicine has found a unique blend of intergenerational play, partnerships, and culturally grounded wellness creating an inclusive space for movement. The program operates as a program of a nonprofit partnership, the $\mathrm{NHI}$, and like all $\mathrm{NHI}$ programs, is very intentionally strength based in all of its elements.

\section{WHO \& WHERE}

Running Medicine takes place in the parks and open spaces of 6 urban and rural communities in New Mexico. It is a year-round program that offers 8- to 10-week seasons. Running Medicine leaders include health professionals and experienced coaches, all of whom are looking to improve their wellness. Running Medicine aims to be inclusive to all, and participants represent a diverse group of Tribes/ethnicities, ages, and fitness and ability levels. In a given community, RM happens 3 or 4 times a week, with intentional elements to create community and allow participants to improve their mind, body, and spirit wellness.

\section{HOW}

Running Medicine "celebrations" begins with an opening circle, often 80 to 100 people strong. A meditation/inspiration/game

Conflicts of interest: authors report none.

\section{Corresponding author}

Anthony Fleg

University of New Mexico

MSC 095040

Albuquerque, New Mexico 87131

afleg@salud.unm.edu is offered to begin the day, followed by dynamic stretches to get muscles warmed up. The youth are in the center of the circle, allowing parents to begin to focus on themselves. We then break up for a 30- to 40-minute walk/run, with a wide range of speeds, abilities, and levels of competitiveness. During this time, we are giving high fives and have additional ways to make the experience communal. The RM closes with static stretching, core strengthening, and a closing inspiration followed by a "handshake line" familiar to traditional American Indian ceremonies. This gives each person a chance to thank the others for their "medicine," and a chance to build community in a very consistent way as the group gets bigger and absorbs new people.

The RM celebrations take place on soft surfaces such as trails and grass, which, along with the stretching and core work, have led to a remarkably low rate of injuries (approximately 2 injuries per 100 people per season). We incorporate healthy food and water at every RM in addition to other "Food is Medicine" elements that encourage people toward healthier eating.

Sprinkle in $160+$ community partners that range from Tribes, health clinics, schools, and nonprofit organizations and you have the RM community approach to building wellness. This leads to intersections with clinic-based programs (eg, diabetes prevention programs). RM allows us to bring our wellness approach to local events, conferences, and as a valuable "classroom" for health professions students that do internships and projects with RM.

Improving physical health, mental health, and social support, along with a culturally grounded approach to exercise are the primary motivations participants list for joining RM. Over $90 \%$ of our participants feel that the program improved their wellness in each of these domains.

\section{LEARNING}

$\mathrm{RM}$ is a powerful reminder that individuals and communities thrive in an environment that creates a low-cost, inclusive place for movement; moreover, this is an important complement to our high-cost, disease-oriented health care system. Keeping an element of "sacred play" and a strength-based model, we find that people explore their needs naturally and lead themselves to healing beautifully well.

To read or post commentaries in response to this article, see it online at http://www.AnnFamMed.org/content/17/5/466.

Submitted February 3, 2019; submitted, revised, February 26, 2019; accepted March 28, 2019. 